\title{
Evaluation of the Phoenix TRUCE Project: A Replication of Chicago CeaseFire
}

\author{
Andrew M. Fox, Charles M. Katz, \\ David E. Choate and Eric C. Hedberg
}

\begin{abstract}
The Phoenix TRUCE Project was modeled after the Chicago CeaseFire program. There have been relatively few process and impact evaluations on the model compared to the level of funding and attention the program has rendered. This paper presents findings related to the evaluation of the TRUCE project. We found that the program engaged in a strong media campaign, conducted conflict mediations, and identified high-risk individuals for case management. The program did not, however, establish a coordinated and collaborative relationship with the faith-based community or other community groups. Time-series analysis showed that program implementation corresponded to a significant decrease in overall levels of violence by more than 16 incidents on average per month, a decrease of 16 assaults on average per month, and resulted in a significant increase of 3.2 shootings on average per month, controlling for the comparison areas and the trends in the data.
\end{abstract}

Andrew M. Fox is an Assistant Professor in the Department of Criminal Justice and Criminology at the University of Missouri- Kansas City. His research interests include social network analysis, gangs, mental health and communities. He received his Ph.D. from Arizona State University. Charles M. Katz is Watts Family Director of the Center for Violence Prevention and Community Safety and is a Professor in the School of Criminology and Criminal Justice at Arizona State University. He received his Ph.D. from the University of Nebraska at Omaha in 1997. His research interests include gangs and gang control, police organizational theory and crime control policy. David E. Choate is the Associate Director of Operations at the Center for Violence Prevention and Community Safety at Arizona State University. He has extensive experience with local, county, state, and federal law enforcement agencies; numerous not-for-profit social service organizations; city, county and state agencies; community groups; and treatment providers throughout Arizona. His research interests focus on problem oriented policing, police-public coproduction of crime prevention and intervention programs, and criminal justice organizational theory. Eric C. Hedberg is a Senior Research Scientist at NORC at the University of Chicago. Dr. Hedberg is an expert analyst of complex survey and multi-level social data using a variety of software packages. He received his Ph.D. in Sociology from the University of Chicago, where he studied statistical methodology and models of social capital processes. Correspondence to: Andrew M. Fox, Department of Criminal Justice and Criminology, University of Missouri-Kansas City, 5215 Rockhill Road, Kansas City, MO 64110-2447, USA.E-mail: foxan@umkc.edu 


\section{FOX ET AL.}

Keywords Phoenix TRUCE; Chicago CeaseFire; violence reduction; violence interrupters; evaluation

\section{Introduction}

In the mid-1990s, the University of Illinois' School of Public Health, led by 5 Gary Slutkin, established the Chicago CeaseFire program. From the start, the Chicago Ceasefire program relied on a public health model that used community mobilization, community awareness, and youth intervention and outreach to focus on reducing retaliatory violence of youth in high gun crime areas of Chicago (Webster, Vernick, \& Mendel, 2009). The program sought to

10 change the behavior of a small number of youth who were at high risk of being victims or perpetrators of gun violence in the near future (Skogan, Hartnett, Bump, \& Dubois, 2008, pp. 8-11). The highly publicized results of the project were remarkable. They showed that the number of shootings declined in several of the targeted neighborhoods by 16 to $35 \%$ and retalia15 tory gang homicides declined by $100 \%$ in each of the five targeted areas (Skogan et al., 2008).

Given the seriousness of the youth violence problem for local, national, and international communities (Pridemore, 2003), the Chicago CeaseFire program represents an important innovation in responding to youth violence (Chaskin, 20 2010). If successful, Chicago Ceasefire can reduce shootings by up to $35 \%$ and virtually eliminate retaliatory shootings in high-violence communities. This would not only have a substantial impact on the victims of violence through the reduction of injury and death, but it would also reduce fear of crime, emotional distress, and health care costs among all members of those communi-

25 ties. To date, however, the utility of the Chicago CeaseFire program for reducing youth violence is largely undetermined because there have been few subsequent replications and evaluations (for exceptions see Skogan et al., 2008; Webster, Whitehill, Vernick, \& Curriero, 2012; Webster, Whitehill, Vernick, \& Parker, 2012; Wilson \& Chermak, 2011).

30 This paper presents our findings on the Phoenix TRUCE project, a Ceasefire replication site, which received technical assistance from Chicago CeaseFire project personnel. While there are a number of differences between Chicago CeaseFire and Phoenix TRUCE with respect to community, program implementation, and evaluation, we believe that the implementation of the program, and its subsequent evaluation, will allow researchers and policy-makers to further understand the generalizability of the impact of the Chicago CeaseFire program on gun violence. The purpose of this paper is to examine the impact of the Phoenix TRUCE project on violence and shootings through a quasi-experimental longitudinal design. In the sections below, we present the Ceasefire Model, prior research on the model, and our methodology for evaluating the Phoenix TRUCE Project. 


\section{The Chicago Ceasefire Model}

Today, the Chicago CeaseFire program (now known as Cure Violence, will be referred to as CeaseFire) is a popular strategy for addressing gun violence. It has been implemented in several American cities, including Baltimore, Kansas City, New Orleans, New York City, Albany, Buffalo, Oakland, Philadelphia, as well as in several locations throughout the world, including Iraq, England, South Africa, and Trinidad and Tobago (ceasefirechicago.org, 2012). CeaseFire was designed to focus on those select few who are the most at risk for "being shot or being a shooter" in the near future. It also attempts to change norms about violence among targeted individuals and neighborhoods by altering how they perceive the short- and long-term prospects of violence (Skogan et al., 2008). The CeaseFire model calls for the implementation of several core strategies for the purpose of having an impact on the decision-making process of those who are involved in shootings. The goal is to reduce the risk that the youth will engage in violence which, over time, will result in changing the norms toward violence in the community.

One of the primary elements of the CeaseFire model is identification and detection (Maguire, 2012). The model is centered around the concept of enhancing a community's capacity to identify and target its high-violence neighborhoods and individuals. Prior research suggests that a small number of people, places, and guns (Sherman \& Rogan, 1995) are disproportionally responsible for gun violence. By targeting scarce resources on these focal points, implementers can direct interventions toward those people, places, and guns that need the greatest attention. Prior research has shown that programs and strategies that accurately diagnose the problem are significantly more likely to impact violence (Klofas, Hipple, \& McGarrell, 2010). The CeaseFire model, therefore, emphasizes thorough analysis to identify those individuals and neighborhoods that are most at risk for imminent violence (Webster et al., 2009).

Another core component of the CeaseFire Model is community mobilization, which involves faith-based leaders, community coalitions, and public campaigns against violence. Community mobilization efforts are largely concentrated on altering the norms and values of the community away from violence and toward the peaceful resolution of conflict. To do this, community mobilization tactics often include the development of community coalitions with the involvement of schools, churches, businesses, residents, and public health and criminal justice agencies. Together, these groups develop a community commitment toward reducing violence while addressing the underlying structural causes of neighborhood violence. They also coordinate anti-violence services that successfully change cultural and behavioral norms and increase the community's capacity to respond to violence (Skogan et al., 2008; Webster, Whitehill, Vernick, \& Curriero, 2012). The most widely recognized aspect of mobilization efforts are typically found in their public education campaigns 
which rely on flyers, posters, pamphlets, t-shirts, and other forms of media, to promote nonviolence in the community.

In addition to violence identification and community mobilization, the CeaseFire model emphasizes the role of outreach workers and violence interrupters. Both of these positions call for the employment of individuals who

10 possess unique street knowledge and credibility. They are typically from the targeted neighborhood and are often former gang members and drug dealers who were involved in serious criminality and violence. Outreach workers are largely responsible for case management, conflict mediation, and mentoring which means it is important for them to hold more complex and personalized

15 relationships with clients. They help clients find jobs, counsel them on alternative methods for dealing with conflict, and help them address underlying risk factors for violence (Skogan et al., 2008; Webster, Whitehill, Vernick, \& Curriero, 2012). Violence interrupters are more specialized and are largely responsible for identifying and responding to retaliatory violence before it

20 intensifies (Ritter, 2009). While outreach workers are typically full-time employees of the program, violence interrupters may be volunteers, or if they are employed by the program, it is on a part-time basis with minimal pay (Skogan et al., 2008).

\section{Prior Research on the Ceasefire Model}

The Phoenix TRUCE Project was modeled after Chicago CeaseFire, which has been replicated in a number of different cities in the United States and internationally. However, there have been only a few formal evaluations of the program. Outside of Chicago, for example, only three sites, Newark, Baltimore, and Pittsburgh, have been formally evaluated. As will be discussed below,

30 some have argued that there were substantial implementation differences between Chicago CeaseFire and the programs replicated in Newark and Pittsburgh. As a result they argue that the findings attributable to the latter programs should not necessarily be generalized to the CeaseFire model (C. Kane [personal communication, May 3, 8 and 16, 2012]). Below, we review the results of the four prior evaluations, discussing their results and implications for understanding the effectiveness of CeaseFire.

\section{Chicago CeaseFire}

Chicago Ceasefire began in 1999 and eventually was implemented in 27 target areas. Skogan et al.'s (2008) evaluation reported that outreach workers played

40 a key role in the program. The outreach workers managed caseloads of high-risk individuals who they determined were the most likely to shoot or to be shot at. The impact evaluation of Chicago CeaseFire relied on 16 years of data that focused on violent crime trends; specifically violent shootings and 
killings. These data were used to compare violent crime trends in seven targeted areas with the violent crime trends in seven matched comparison areas (Skogan et al., 2008). Given the complexity of the project-multiple sites, city-wide trends-time-series analyses were employed to examine its impact. Additionally, the authors used social network analysis to examine whether gang homicide networks weakened over time.

Skogan et al. (2008) found that in four sites CeaseFire was associated with "distinct and statistically significant declines" in actual and attempted shootings. The authors also reported that the declines of violence in these areas ranged from 16 to $35 \%$, while six of the sites were reported to be "noticeably safer" as a result of the CeaseFire program. Also, increased safety was measured by decreases in size and intensity of shooting hotspots and the evaluators credited the decrease of violence in four of the six sites, to the introduction of CeaseFire. Additionally, using social network analysis, the authors reported that gang homicide density decreased in two of the sites, retaliatory gang killings decreased in four of the sites, and gang involvement in homicide decreased in three of the sites. As a result of these findings, the evaluators concluded that the program had a strong potential to reduce shootings and killings (Skogan et al., 2008).

However, Maguire (2012), suggested that the above results were not as straightforward as they may appear. Through a lengthy post hoc analysis of the evaluation, Maguire (2012) points out that the evaluation by Skogan et al. (2008) focused on three outcome measures in seven zones for a total of 21 outcome measures. Through a re-presentation of these results, Maguire (2012) illustrated that "among the 21 sets of outcomes, 12 favor the comparison areas .., 8 favor the treatment areas ..., and 1 favors neither ..." (pp. 8-10). Maguire (2012) also noted that the social network analysis examining reciprocal shootings was similarly interpreted in an optimistic fashion. Among the eight sites where retaliatory shootings were examined, retaliatory shootings were reduced in half. In the other half, no demonstrable change was exhibited.

It is unclear what factors might have caused a decline in reciprocal shootings in half the areas, while the other half of the areas was not affected. For example, Project Safe Neighborhoods (PSN) was carried out at the same time and in $50 \%$ of the same locations as Chicago CeaseFire (Papachristos, Meares, \& Fagan, 2007). In fact, the authors concluded that, "after controlling for the social, demographic, and PSN factors, no statistically significant effect in the declining homicide rates during the observation period can be attributable purely to the presence of Operation Ceasefire in the PSN treatment areas" (Papachristos et al., 2007, p. 264). These findings when taken together suggest that, contrary to popular belief, the CeaseFire program may not have been as effective in reducing violence as first promoted. 


\section{Operation Ceasefire Newark}

Ceasefire Newark was one of the first near-replication sites in the nation. Because of the high rates of gun violence in Newark, stakeholders were committed to implementing two promising strategies at the time: Boston's Operation Ceasefire and Chicago CeaseFire. In other words, Operation Ceasefire in Newark is a hybrid that implements elements of both the Boston and Chicago programs, for the purpose of reducing gun violence in Newark's most violent neighborhoods.

In 2004, a working group examined available police data and identified a two-square-mile area, later referred to as the Ceasefire Zone (CF Zone), where Operation Ceasefire would later take place. The CF Zone was characterized as having higher rates of gun violence than other neighborhoods in Newark (Boyle, Lanterman, Pascarella, \& Cheng, 2010). The program included five elements of Chicago CeaseFire: public education, community mobilization, youth outreach, faith-based leader involvement, and criminal justice participation. However, Newark CeaseFire differed from Chicago CeaseFire in a few important ways. First, it did not make use of violence interrupters. Second, outreach workers did not employ a case management approach to their clients. Third, Newark

20 CeaseFire employed outreach workers who might have been church congregants as well as ex-offenders (Boyle et al., 2010, p. 107).

Similar to Boston CeaseFire, the police played a strong role in Newark's implementation of CeaseFire. Shooting teams were responsible for the "aggressive investigation of shootings" in the CF Zone. Police were also responsible for notifying CeaseFire partner organizations of shootings for the purpose of mobilizing resources, and for working with parole officers to monitor parolees in the CF Zone. However, while Boston Ceasefire emphasized the importance of "pulling levers" and collective accountability, the Newark Ceasefire project did not employ this strategy. The reason for this is simply because Newark gangs and groups did not possess the organizational structure or cohesiveness that would warrant such an approach (Boyle et al., 2010).

Boyle et al. (2010) examined the effectiveness of Operation Ceasefire through the analysis of admissions to a Level 1 trauma center. Specifically, they examined the number of gunshot wounds that occurred in the CF Zone, as 35 well as a comparison area. ${ }^{1}$ The analysis consisted of a three-year period from 1 January 2004 through 31 December 2006. Time-series analysis illustrated that, in Newark, Operation Ceasefire had no significant impact on the number of gunshot wounds. Some advocates of the Chicago Ceasefire model, however, maintain that these findings are not reflective of the Chicago Ceasefire model,

1. The comparison area was matched and subsequently selected based on the number of gunshot wounds and census data that reflected the target areas ethnicity, age, household income, poverty, and 
given the lack of implementation fidelity delivered in Newark (C. Kane [personal communication, May 3, 8 and 16, 2012]).

\section{Baltimore's Safe Streets Program}

In 2007, the US Department of Justice funded the Baltimore's Safe Streets Program to implement the Chicago CeaseFire program in Baltimore. Initially, the only programmatic difference between Chicago and Baltimore was the use of violence interrupters because violence interrupters were not employed as part of the Baltimore project. Instead, outreach workers were responsible for conflict mediation, as well as for intervening in the lives of at-risk youth. Over time, the program grew from one targeted community (McElderry Park) to five targeted communities (McElderry Park, Union Square, Ellwood Park, MadisonEastend, and Cherry Hills) (Webster et al., 2009; Webster, Whitehill, Vernick, \& Curriero, 2012; Webster, Whitehill, Vernick, \& Parker, 2012).

Daniel Webster and a team of public health scholars from Johns Hopkins served as the evaluation team. They produced a number of public manuscripts documenting program fidelity and effectiveness in the Baltimore sites. The first 20 was an interim evaluation report based on data collected through October 2008, which focused only on the first three sites: McElderry Park, Union Square, and Ellwood Park. Here, the authors reported mixed findings. For example, in McElderry Park homicides declined (particularly among those under age 30), but nonfatal shootings increased, especially when contrasted with the comparison areas. In Union Square, homicides and shootings actually increased in the target area. In Elwood Park, homicides and shootings remained stable; however, nonfatal shootings did decline in the target area (Webster et al., 2009).

In 2012, the evaluators released the final report that examined the impact of the program in four sites-McElderry Park, Elwood Park, Madison-Eastend, and Cherry Hill - relying on data through December 2010. This time the results were more impressive, with three of four neighborhoods reporting a significant decline in homicides and nonfatal shootings. The evaluators claimed that over 112 months, the program in the four neighborhoods had prevented five homicides and 35 nonfatal shootings. Following the public success of the program, in late 2011, the US Department of Justice provided an additional \$2.2 million in funding to support the Baltimore Safe Streets Program (Webster, Whitehill, Vernick, \& Curriero, 2012; Webster, Whitehill, Vernick, \& Parker, 2012).

These findings should be interpreted with caution, however. Three of the five program implementation sites (Ellwood Park, Union Square, and MadisonEastend) were shut down shortly after being established. Several local news stories focusing on the program revealed that the Union Square site was closed after one year as a consequence of the city terminating its contract with the local nongovernmental organization (NGO) that managed the site. The city learned through local and federal law enforcement that a local street gang 
(the Black Guerilla Family) had infiltrated the program. Gang members, one of which was a gang leader, were working for the Union Hills Safe Streets site as outreach workers for the purpose of obtaining cover for their gang's heroin distribution network (Fenton, 2012; Kelly, 2010). Two other sites-Ellwood Park and Madison-Eastend - closed in 2010, but little information about the reason for their closures has been revealed in the media or interim, final, or peerreviewed manuscripts (see Webster et al., 2009; Webster, Whitehill, Vernick, \& Curriero, 2012; Webster, Whitehill, Vernick, \& Parker, 2012). These closures suggest that implementation and/or the sustainability of such complex programs might be difficult.

\section{Pittsburgh's One Vision One Life}

Pittsburgh's One Vision One Life (otherwise known as One Vision) program was established as a result of several grass roots organizations joining together to

15 seek an innovative evidence-based response to violence in Allegheny County. Community leaders began by diagnosing the County's violence problem and conducting research on best practices. Following consultation with partners and the police, the Pittsburgh program was "modeled after (but [did] not mirror)" Chicago and Baltimore CeaseFire programs (Wilson \& Chermak, 2011,

20 p. 995). The One Vision program adopted a six-point plan to reduce shootings. The plan consisted of (1) mediating and intervening in conflicts, (2) providing outreach to at-risk youth, (3) building strong community coalitions, (4) publicizing a no-shooting message, (5) rapidly responding to violence in target areas, and (6) developing programming for at-risk youth (One Vision One Life, no date). The One Vision program was more similar to Baltimore than Chicago in its use of outreach workers. Community coordinators served as generalists, addressing a variety of community needs, and were responsible for conflict intervention, mediation, and other outreach work with at-risk youth. Others have also noted that One Vision was different from Chicago CeaseFire with

30 respect to police participation in the project. Specifically, in Pittsburgh, community coordinators rarely conferred with the police, and when they did, the interaction was often negative (Maguire, 2012).

A rigorous evaluation of the One Vision program was conducted by Wilson, Chermak, and McGarrell (2011). The evaluators relied on a quasi-experimental 35 design comparing three target areas to matched comparison areas. Wilson et al. (2011) found that program implementation either increased or did not affect homicides. Further, they reported that the program increased aggravated assaults and gun assaults in the target areas (Wilson et al., 2011). Wilson et al. (2011) caution that the implementation of the Chicago CeaseFire model has varied by site and that researchers do not yet know which components, or aspects of each component, have the most impact on gun violence. For example, while outreach workers in Pittsburgh engaged in more community mobilization than outreach workers in other sites, it is not clear whether or not the 
activity of the outreach worker plays a unique role in increasing or decreasing shootings. Thus, Wilson et al. recommended that future evaluations should continue to examine how the different levels of implementation are related to the impact of the program.

\section{The Phoenix Truce Project}

The Phoenix TRUCE Project was modeled after the Chicago CeaseFire program, and as such, had adopted a public health approach in responding to violence in the community. By focusing attention on the gun violence, TRUCE sought to first and foremost diminish shootings. Other potential reductions in crime and community improvement were expected, but were not necessarily the primary focus of the TRUCE effort. TRUCE used carefully selected outreach workers and violence interrupters with ties to the local community. The outreach workers recruited members of the community who were identified as being at risk of being potential victims and or perpetrators of gun violence. Outreach workers were to use a set of seven criteria to help them guide client selection by assessing each potential client's appropriateness for inclusion in the TRUCE caseload. Individuals possessing four or more of the seven criteria were considered high risk, making them good candidates for recruitment. The seven at-risk criteria were: (1) Gang involvement; (2) Key role in a gang; (3) Prior criminal history; (4) Recently released from prison; (5) High-risk street activity; (6) Recent victim of a shooting; and (7) Young (aged 16-25 years old).

The lead agency of the Phoenix TRUCE project was Chicanos Por La Causa, Inc. (CPLC). CPLC is a statewide organization with 800 employees, 40 years of experience, and the resources needed to develop, implement, sustain, and manage programs and services. At this point in time, the CPLC had 26 years of experience in community-based prevention. It is considered by many in the

state to be one of the premier NGOs serving the Hispanic/Latino community. ${ }^{2}$ CPLC received technical assistance from the Chicago Project for Violence Prevention (CPVP), which was responsible for the creation of the Chicago CeaseFire model. CPVP provided street outreach and violence interruption skills training to the Phoenix TRUCE team, while lending ongoing violence prevention program and planning support.

The Phoenix TRUCE target area is located in the South Mountain area, and is largely comprised of some of the city's oldest homes and businesses. The community is comprised of deeply rooted intergenerational gangs, dilapidated

2. CPLC's Director of Prevention was responsible for fiscal and contract management. The Program Manager oversaw implementation and supervised project staff. The Prevention Services Coordinator was responsible for community partnerships and coordinating prevention efforts among partners. Outreach staff consisted of four outreach workers (one of which was the supervisor) and four violence interrupters (this went down to two toward the end of the project). Outreach workers and violence interrupters were two distinctly separate positions. 
properties, and an emerging and shifting neighborhood composition, which makes it a community in a stressful transition that has been the subject of prior research (Portillos, Jurik, \& Zatz, 1996; Zatz \& Portillios, 2000). South Mountain is challenged by high-crime rates, a struggling economy, and urban decay. Most alarming is the disproportionate use of firearms to commit crime. The Arizona Department of Health Services (AZDHS) reported that $80 \%$ of homicides were firearm related in South Mountain (Shacter, 2009). Related, the Phoenix Police Department's South Mountain Police Precinct experienced a large increase in violent crime in 2007. During the first 11 months of 2007, 62 homicides were committed, a $41 \%$ increase over the previous year. Hermoso Park, a neighborhood within the South Mountain area was selected as the target area for the TRUCE project given its high level of violence. The Hermoso Park neighborhood is approximately 1.5 by 1 mile in size and has about 12,000 residents. While the majority of its residents are Hispanic (54\%), it has one of the highest proportions of African-American residents in the city (40\%). Its median household income is about $\$ 34,000$ a year, which is substantially lower

20 than the rest of the city. Consistent with the goal of appropriately diagnosing the problem, the above information was used to identify the Hermoso Park community as the best target area. It was found to be a good fit for the program, given the violent crime incidents and population characteristics of the community (Skogan et al., 2008). One possible concern was that while the geographic size of Hermoso Park was consistent with the Chicago model, it was much less densely populated.

\section{Methodology}

In order to evaluate the Phoenix TRUCE project, we conducted both the process and impact evaluation; both are described below. The process evaluation

30 examined the extent to which the community and target populations experienced the TRUCE project. The impact evaluation, in turn, measured how variations in TRUCE dosage were related to variations in violent crime in the target area.

In conducting the process evaluation of the Phoenix TRUCE project, we relied on data pertaining to the implementation process and specific intervention activities. The process evaluation was organized around the five core components of the Phoenix TRUCE project, which were aligned with Chicago CeaseFire model. The five components are: (1) Community mobilization; (2) Youth outreach and intervention; (3) Faith-based leader involvement; (4) Public education; and (5) Criminal justice participation.

The data used to examine the project's implementation were primarily collected from two sources, including interviews and observations of TRUCE staff and other stakeholders and the Chicago Project for Violence Prevention Evaluation Database. First, semi-structured interviews were conducted regarding the implementation process and programmatic activities. In all, 12 semi-structured 
interviews were conducted with TRUCE staff members and project stakehold-ers. Interviews took place between June 2011 and October 2011. Related, the evaluation team regularly attended project functions, activities, and partners'meetings. Second, the Project for Violence Prevention Evaluation Database was examined. The database is an online system developed for use by Chicago

CeaseFire model sites (such as Phoenix) for use in recording and evaluating important components of CeaseFire sites. The system integrates recording and reporting tools for participant intake, shootings, violence interrupter logs, conflict mediations, and community activities. This detailed level of data for intervention activities provided a quantitative base for evaluating the implementation of core components.

The impact evaluation relied on a pre-test/post-test nonequivalent control group design. The methodology relies on a target area where the intervention takes place and three comparison areas, which were purposely matched as closely as possible to the targeted area. Data were collected from target and comparison areas before and after programimplementation.

We identified comparison areas by constructing a disadvantage index score for all census blocks in Phoenix. This allowed us to identify areas of the city that were most comparable to the targeted area. After we scored each block group, census, police, and hospital data were used to identify five contiguous block groups (the size of the target area) that best matched our target area. As a result, we identified three comparison areas. ${ }^{3}$ Table 1 presents information on the characteristics of each area. The comparison areas were matched well with the target area with respect to such neighborhood characteristics as population, number of households, vacant housing, household income, and ER visits for violence. ${ }^{4}$ There was one important difference between the target and comparison areas. We were unable to identify any comparison area with a similar ethnic composition as our target area. About $40 \%$ of the residents in the target area were African-American compared to 10, 6, and $4 \%$ of those in the comparison areas. The target area is comprised of the largest proportion of African-American residents in the city (as measured within 5 continuous block groups), and no other neighborhoods had a similar proportion of African-American residents.

3. The authors were not aware of at the time, nor have any come to light since the end, of any other initiatives addressing violent crime in any routinized or programmatic manner in the target area or control areas during the study period. While policing activities and enforcement in highcrime areas are always ongoing and might impact any programmatic effects, both positively and negatively, we have no information that policing efforts were fundamentally different before, during or after the implementation period effecting the data used in our analyses.

4. Although two of the comparison areas had noticeably higher numbers of violent crime incidents reported to police, the areas were matched well in terms of structural disadvantage indicators. The comparison areas were used to control for trends in violent crime within areas of the city that are similarly situated during the study period. It is often difficult to identify identical control areas, however, the control areas allowed us to remove trends in the data that were present in other areas of the city and which the project could not reasonable account for. 


\section{FOX ET AL.}

Table 1 Characteristics of target and comparison areas

\begin{tabular}{lrrrr}
\hline Area & Target & Area A & Area B & Area C \\
Total population ${ }^{1}$ & & & & \\
Total households & 11,771 & 11,749 & 11,294 & 12,519 \\
Total housing units & 3,220 & 3,303 & 2,862 & 3,018 \\
Vacant housing units & 3,322 & 3,581 & 2,986 & 3,172 \\
\% of units vacant & 102 & 278 & 124 & 154 \\
\% White & 3 & 8 & 4 & 5 \\
\% Black & 22 & 45 & 57 & 49 \\
\% Hispanic & 40 & 4 & 10 & 6 \\
Median household income & 54 & 65 & 82 & 81 \\
& $\$ 34,426$ & $\$ 38,447$ & $\$ 35,490$ & $\$ 33,961$ \\
Total violent incident reports 5/09 to $5 / 10$ & 551 & 781 & 790 & 537
\end{tabular}

'Based on ESRI 2008 Census Estimates.

We measured the impact of the project using incident report data from the Phoenix Police Department (PPD). The PPD provided their Computer-Aided Dispatch (CAD) and Record Management System (RMS) data. These included all incidents reported by the police from 1 January 2007 through 31 December 2011 (60 months) for the target and three comparison areas. Our analyses plan initially paralleled Wilson and Chermak's (2011) by focusing on three incident types, which were aggregated monthly: homicides, shootings, and assaults ${ }^{5}$; and we also added another crime category that included all violent incident reports ${ }^{6}$. In the end, however, homicides were not included as an independent

5. While the initial Chicago CeaseFire program did not focus on assaults, replication sites such as Pittsburgh and Denver have used assaults as an outcome variable. Additionally, over the past several year's solicitations for OJJDP's Community-Based Violence Prevention Demonstration Program, which is a major funding mechanism for CeaseFire/Cure Violence replication sites, requires applying sites to demonstrate a violence problem related to three specific measures: assaults, shootings, and homicides. These three measures are the same as those used by Wilson and Chermak and in the present study. We believe that the inclusion of assault as a primary outcome measure was also important for several other reasons. First, and perhaps more importantly, Wilson and Chermak's finding that CeaseFire was related to a significant increase in assaults has shifted much of the policy discussion surrounding the efficacy of CeaseFire. If other replication sites determine that the program increases assaults it might suggest evidence of a boomerang effect. Second, researchers have long known that the dynamics of assault are like those of homicide in a number of ways such as time of day, day of week, age, ethnicity, and gender of the offender and victim (Pokorny, 1965). Related, researchers have long found that the developmental processes associated with assaults and homicides are similar (Felson \& Steadman, 1983). Third, prior research conducted in South Phoenix revealed that the dynamics of assault are similar to the dynamics of shootings and homicides (Arizona Criminal Justice Commission, 2004). Last, the CeaseFire model has evolved and is currently being used to address nongun related assault (Decker, Featherstone, Cantillon, \& Slutkin, 2013).

6. This included only homicides, misdemeanor and felonious assaults, robberies, shootings, and other misconduct with a firearm. 
crime category because the base rate was too low. In the year preceding the Phoenix TRUCE project, there had been only three homicides in the target area, and while in the post-implementation period homicides declined to just one (during implementation there were 4 homicides and 17 shootings), the numbers were far too low to conduct any meaningful analysis. Analyses of these data alone would have resulted in low power, and we would have been unable to detect a significant change. ${ }^{7}$

We examined change by comparing the police data 41 months pre-implementation to the 19 months post-implementation. ${ }^{8}$ Police data consisted of dispatched calls for service (CFS), officer-initiated events, and callbacks, all of which were derived from the Phoenix Police Department's CAD/RMS system. As mentioned above, incidents recorded by the police were coded into one of three designated categories (i.e. assaults, shootings, and all violent crime) or were removed from the analysis. Incidents described as "shootings" or "shots fired" were compiled for our shooting measure. Our assault measure was created by aggregating the following incident types: assault, attempted assault, aggravated assault, attempted aggravated assault, cutting or stabbing, attempted cutting or stabbing, subject threatening, and fighting. The measure for all violent incidents included the incidents described above, as well as the following: purse snatch, attempted purse snatch, strong armed robbery, attempted strong-armed robbery, armed robbery, attempted armed robbery, subject with a gun, misuse of weapon, and homicide.

We use a number of time-series models to assess the effects of different forms of "dosage" on the outcome, while controlling for the trends in the comparison areas. ${ }^{9}$ Specifically, we used pooled cross-sectional time-series analysis. This type of analysis, for example, allows for the fact that the number of police incident reports in one month is related to the number of calls in the previous month (temporal autocorrelation). Additionally, the model allows for the fact that the target area and comparison areas might all be affected in the same way in a given month for an unobserved exogenous reason. Across all models, we control for changes in crime that might be seasonal (by month).

7. Additional data were available on emergency room visits; however, these data were not used as an outcome because of the low cell counts.

8. A longer evaluation period would have been ideal, however, the project was supported by a large federal grant and much of the activity slowed or stopped at the end of the grant cycle.

9. We investigated the possibility that increases in violence could trigger increases in dosage by lagging the dependent variable (hence, holding constant previous violent crime associated with increase in dosage) and our results did not change. The more parsimonious models are presented here. Additionally, further investigation was conducted on the temporal trends with both the predictor and outcome since correlations are possible even without a direct relationship. We confirmed these temporal trends with a set of Dickey-Fuller tests. We ran simulations to confirm this, creating two trending variables that were uncorrelated. We also found that our fixes (including allowing for a correlated error structure, lagging the dependent variable, lagging the independent variable) did not produce the nonsignificant results that would prove a remedy in our simulations. 
This longitudinal, multivariate technique allowed us to isolate the program effects as best as possible (Podesta, 2000). ${ }^{10}$

\section{Implementation Findings}

First, we examined process findings related to youth outreach and intervention in terms of program dosage, conflict mediation, client selection, and risk reduction activity. Second, we examined the public awareness and messaging they received. Third, we examined criminal justice participation. And finally, we examine other issues that emerged during program implementation.

Youth outreach and intervention took place either through an outreach worker or a violence interrupter. In terms of contacts, there was an average of more than 300 contacts per month between outreach workers and clients, of which on average $42.4 \%(\mathrm{M}=127.6, \mathrm{n}=2,297)$ were conducted face-to-face in the client's home or on the street in their community. On average, outreach workers made 45.9 contacts per client. As shown in Table 2, there were a total of 118 clients during implementation. Caseworkers made 5,381 contacts across 118 participants. The most common type of contact was made by phone $(\mathrm{n}=$ $2,031,37.7 \%)$, closely followed by home visits $(n=1,392,25.9 \%)$. Phoenix TRUCE personnel made face-to-face contacts with clients in the community $42.4 \%(\mathrm{n}=2,297)$ of the time. All clients had at least one face-to-face contact since their intake date, with $84.7 \%(\mathrm{n}=100)$ of clients having five or more face-to-face contacts. The average number of total face-to-face contacts per client was $39.1(n=5,414)$. As seen in Table 2, 64.3\% of all contacts lasted 60 min or less. The overall average length of a contact was from about an hour to an hour and $15 \mathrm{~min}$.

Violence interrupters distinguish the CeaseFire model from other community-based crime prevention efforts. The role of the violence interrupter

30 demands that one maintain a difficult balance. It requires individuals with a history of crime and violence, yet who are removed enough from that time to value a life and community without the violence. The importance of credibility on the streets was summarized succinctly by one of the TRUCE stakeholders: "If you not real with this job, you really in the wrong place, because somebody going to hurt you." One of the main activities of violence interrupters and

10. Prior to the interpretation of the findings we examined statistical power; or our ability to detect whether an effect exists. Statistical power is a function of four elements: sample size, sample variance, statistical significance level, and effect size (Cohen, 1988). Our power analyses revealed that our samples had sufficient sample size to detect effects. For example, our t-tests comparing the mean number of shootings between the target group and Area B have statistical power of .83 to detect medium effects (Cohen's $\mathrm{d}=.50$ ). Our comparisons between pre- and posttest periods yielded similar results. In the target and comparison areas, for instance, our t-tests have power of .99 to detect medium effects. Such post hoc statistical power analyses are typically only a major concern in analyses that fail to detect differences or effects. In the present study, however, we detected a number of compelling findings. 
Table 2 Summary of program dosage

\begin{tabular}{llcr}
\hline & & $\mathrm{N}$ & $\%$ \\
\hline Number of clients & & 118 & 100 \\
\multicolumn{1}{l}{$\begin{array}{l}\text { Number of contacts } \\
\text { Type of contact }\end{array}$} & & 5,381 & 100 \\
& Phone & & \\
& Home & 2,031 & 37.7 \\
& Street & 1,392 & 25.9 \\
& Office & 548 & 10.2 \\
& Other & 357 & 6.6 \\
& Othe & 1,053 & 19.6
\end{tabular}

Time spent with clients

$\begin{array}{lr}30 \text { minutes or less } & 1,78 \\ 30-60 \text { minutes } & 1,697 \\ 60-90 \text { minutes } & 72 \\ 90-120 \text { minutes } & 51 \\ 120-150 \text { minutes } & 542 \\ 150-180 \text { minutes } & 17 \\ 180-210 \text { minutes } & 38 \\ 210 \text { minutes or more } & 30\end{array}$

$\begin{array}{ll}1,781 & 32.9\end{array}$

$1,697 \quad 31.4$

$722 \quad 13.4$

$510 \quad 9.4$

$542 \quad 8.4$

$178-3.3$

$38-7$

$30 \quad .6$

Conflicts mediated

Reason for conflict

Gang

Personal altercation

Domestic violence

outreach workers was to stop impending violent conflicts in the target area. TRUCE staff became aware of conflicts in a variety of ways, and then made contact with the parties involved in an effort to help negotiate a peace to reduce the likelihood of shootings. As seen in Table 2, the Phoenix TRUCE project engaged in 58 conflict mediations from June 2010 through December 2011. Table 2 shows that gang issues were the most frequent source of conflict ( $\mathrm{n}=27,46.6 \%)$.

TRUCE outreach workers followed the CeaseFire model in selecting clients for the case management and risk reduction components of the program. The model calls for potential clients to be identified as high risk for involvement in gun violence, either as victims or perpetrators; using a rubric of seven at-risk characteristics: (1) Young-aged 16-25 years old, (2) Prior history of offending, (3) Gang involvement, (4) Key role or position in the gang, (5) Involvement in high-risk street activity, (6) Recently released from prison, (7) Recent victim (past 90 days) of a shooting. 
Consistent with the Chicago CeaseFire Model clients were recruited for Phoenix TRUCE only if they were assessed as having four of the seven selection criteria listed above, thus placing them in the "high-risk" category. At the time of this analysis, a total of 118 clients had been fully enrolled; all of whom met at least four of the selection criteria. ${ }^{11}$ As seen in Table 3, most clients were male $(\mathrm{n}=86,72.9 \%)$ and the majority of clients were Black/African-American $(\mathrm{n}=93,78.8 \%)$. The findings indicated that there was substantial program fidelity in that TRUCE workers selected the appropriate high-risk individuals on whom to focus their attention. The most common of the seven risk factors among clients, as seen in Table 3, was being involved in a gang, with $89 \%(\mathrm{n}=$ 105 ) of clients identified as such. Gang membership was closely followed by involvement in high-risk street activity $(n=100,84.7 \%)$. More than two-thirds $(\mathrm{n}=79,66.9 \%)$ of clients were between 16 and 25 years old, and most held a key position in the gang $(n=67,56.8 \%)$. Thirty-three clients $(28 \%)$ had been recently released from prison. Being a recent (past 90 days) victim of a shooting was the least frequent criterion present; although this described more than a quarter $(n=31,26.3 \%)$ of the clients. Thus, the typical TRUCE participant was someone between the ages of 16 and 25, gang involved, with a history of violent crimes, and currently involved in high-risk street activity.

20 A review of the client management database with respect to the quantity and quality of case management also indicated the Phoenix TRUCE project was implemented with a great deal of fidelity during the project. As shown in Table 3, outreach workers assisted $19.5 \%$ of clients with job readiness and $25.4 \%$ with job preparation. ${ }^{12}$ Clients were referred to substance abuse treatment programs (13.6\%), educational programs (26.3\%), and anger management programs $(10.2 \%)$ when the outreach worker felt it was appropriate. During the interactions with clients, outreach workers reported having discussed employment during $15.6 \%$ of the contacts, substance abuse during $10.8 \%$ of the contacts, emotional issues during $23.9 \%$ of the contacts, and nonviolent conflict

30 resolution and problem-solving during $48.4 \%$ of the contacts. Additionally, outreach workers helped mediate 51 conflicts during client contacts. In summary, both the frequency and general tenor of the contacts demonstrated a good dosage of client outreach effort.

In addition to the youth outreach and intervention, process measures indicated that the Phoenix TRUCE project was actively involved in increasing com-

11. All clients were identified by the outreach workers or violence interrupters and were subsequently assessed for inclusion in case management. It is our understanding that all of the clients lived in the target area. Although official criminal history records are not available for these clients, it does appear that the project identified a large group of high-risk individuals in the target area for participation in case management.

12. Job readiness focused on issues related to appropriate clothing for job seeking and job keeping, acquiring appropriate legal documents and identification for proof of employment eligibility, and transportation needs. Job preparation consisted of learning how to locate job openings and complete employment applications, preparing a resume, and practicing successful interviewing techniques. 
Table 3 Summary of client selection and risk reduction

$\mathrm{N}$

Client selection

Number of clients

118

100.0

Gender

Male

Female

Race

African-American

Latino

Native American

Caucasian

Total

Client risk factors

Gang involved

Core gang member

67

Prior criminal history

72.9

Recent victim of violence

78.8

16.9

2.5

1.7

100.0

Aged 16-25

Recently incarcerated

89.0

56.8

84.7

26.3

66.9

28.0

High-risk client (four or more criteria)

100.0

Risk reduction

Number of clients

$\begin{array}{rr}118 & 100.0 \\ 23 & 19.5 \\ 30 & 25.4 \\ 16 & 13.6 \\ 31 & 26.3 \\ 25 & 21.2 \\ 12 & 10.2 \\ 5,381 & 100.0 \\ 839 & 15.6 \\ 587 & 10.9 \\ 1,284 & 23.9 \\ 2,621 & 48.7 \\ 51 & .9\end{array}$

Assisted with job readiness

19.5

Assisted with job preparation

25.4

Substance abuse treatment referrals

13.6

Education program referrals

21.2

Client was unemployed

10.2

Anger management referrals

Number of client contacts

Discussed employment

15.6

Discussed substance abuse

Discussed educational issues

Discussed problem solving

munity awareness about the costs of violence. This was done to enlist broad-based community support for changing attitudes and behaviors related to violence. More than 188 community activities and events were held over the project period. The activities and events included community gardens $(n=98)$, canvassing the neighborhood $(n=29)$, holding barbeques $(n=21)$, community association meetings $(n=9)$, peace marches $(n=4)$, and other client and community-focused activities $(\mathrm{n}=29)$. Related, data obtained from stakeholders indicated that a large number of educational materials were distributed as part of the projects implementation. Specifically, more than 11,000 public 
education materials were distributed throughout the project. For example, 4,000 door hangers, 3,500 fliers, brochures, postcards, and posters, 1,500 wrist bands, and 1,150 t-shirts and hats were distributed. ${ }^{13}$

Criminal justice participation in TRUCE was largely focused on the local police. The police shared information with TRUCE staff about neighborhood violence, provided security during events, attended partner meetings, and were generally supportive of requests by partners. As expected, outreach workers and violence interrupters kept a healthy distance from the police in public. This was in part because they were concerned about their street image. Specifically, they were concerned that their clients would not trust them if they knew that

15 they talked to the police. Regardless, the police fulfilled all expectations asked of them by CPLC, and most importantly interviews with outreach workers and violence interrupters indicated that the police often shared information with them, which allowed TRUCE to target clients for services.

In terms of overall implementation, interviews with key stakeholders indicated that over the course of the project there were two problems related to the implementation of Project TRUCE. The first was related to programmatic community embeddedness. Specifically, project TRUCE lacked a community advisory board and faith-based involvement. Second, we found that the geographic space of Phoenix did not lend itself well to the replication of the Chicago CeaseFire model. Chicago protocols and technical advisors call for the program to be implemented in geographically small and dense (both with respect to population and gun violence) neighborhoods. These types of neighborhoods simply do not exist in Phoenix. As the TRUCE project progressed, one of the major issues confronting CPLC and the technical advisors in Chicago,

30 was related to the appropriateness of the target area, which became a source of contention between the stakeholders in Phoenix and Chicago. At the heart of the issue was the question: by what factors are sites to identify and select an appropriate target area? Related, how does a city's concept of community play a role in the implementation of the CeaseFire model?

Many of the Phoenix stakeholders felt the target area was too small and that in order to better address the violence problem in the area it should be expanded. For example, one stakeholder stated,

Out here in Phoenix, South Phoenix, you can take a bus for a long time and not worry about anything or walk blocks and not worry about anything, there is gangs yes, there're different gangs, different sets but at least, it's not so congested. It's not congested and that's one of my biggest, I always debate when it come to this, it's like, it's not the same as [Chicago].

13. The TRUCE anti-violence message was fairly general. The TRUCE slogan was "Start the Peace. Stop the Violence." Most of the fliers, postcards, and brochures had pictures of a community member, violence interrupter, or outreach worker with the quote, "We've committed to a life of non-violence. You can too." One set of postcards also laid out the legal consequences of illegally carrying

or using

a

gun. 
On the other hand, stakeholders from Chicago expressed the need to have a target area that was geographically small enough to walk, but had a high con- centration of gun incidents. One technical advisor from Chicago stated:

5

[CeaseFire is] predicated on having a large enough concentration, you know, of a problem in order to impact that problem. And the model that we use, you have to get to know the people who are most closely associated with the problem and have some sort of effect on them and for those people that you really are looking to change, or help change over the long term, that requires, we think, fairly intensive contact. You know, three face-to-face a month, three home visits a month, daily phone contact or frequent phone contact. You know, it is pretty intensive and it becomes more difficult to do that when you are chasing all over the place. So from a practical point of view, we think it is difficult to do the model. [if the area is too large]

CPLC staff repeatedly noted that the concept of a self-defined neighborhood that is walkable and has the concentration of violence equal to neighborhoods in Chicago did not exist in Phoenix. The urban geography looks and feels different, and the density of residents and gun crime is much lower. ${ }^{14}$ In the end, given the requirements of the Chicago technical advisors, most of those involved in the Phoenix TRUCE project questioned whether the CeaseFire model could be adapted to cities that look and feel so different than Chicago. As one Chicago technical advisor stated, “... it may be that this is, either the target area wasn't the right target area, or it could be that maybe this model isn't appropriate for this city. That's possible too." Others noted that some adjustments might need to be made to accommodatecities with different geographical space, from the size of the target area to the time of day and week that outreach staff routinely work. One Phoenix stakeholder summarized this by saying, "Do I feel that we can make it like CeaseFire? Yes, we can. Do I feel like, that we can make it with the same concept they have? No, I don't. No, I don't. We gotta, I feel that Phoenix, it's a complete different city [than Chicago]."

\section{Impact Findings}

To measure the impact of the TRUCEproject we examined its effect as a whole and also how the specifics of the youth outreach, in terms of dosage, client selection and risk reduction (summarized in the above section), were related to changes in crime. We first examined the impact of the TRUCE project on violence and shootings in the target area by assessing the within-area trends in the outcome data. This section examines whether there were any significant changes in the average number of incidents before and after the 


\section{FOX ET AL.}

implementation of the TRUCE project. We conducted a t-test for difference of means for each area between the 41 months prior to implementation and the 19 months following implementation. Table 4 displays the results. The analysis showed that for the target and comparison areas there were no significant changes in the number of shooting incidents, or the overall number of violent incidents, between the pre-implementation period and the post-implementation period. With respect to assaults, there was one significant change in comparison area A where the mean number of assaults increased from about 59 per month in the pre-implementation period to about 67 per month in the post-implementation period. Given the lack of meaningful within-area significant differences, we did not compare between areas.

Next, we controlled for trends in the data, both within the target and comparison areas, through time-series analysis. Different models were run to assess the overall effect of the TRUCE program and to assess the impact of program dosage, attention to risk reduction, and client characteristics. Timeseries analysis allowed us to assess those activities that might have the greatest impact on overall violence, shootings, and assaults. The analyses presented below are for the programmatic effects only. Each effect corresponds with a unique cross-sectional time-series model, all of which can be found at 20 [www.omitted for review purposes]. The full models control for the levels of violence in the comparison areas, the trends in the data over time, and any seasonal effects that could be related to a greater number of incidents during specific months of the year.

Table 4 Change in police incident reports pre-post truce implementation

\begin{tabular}{|c|c|c|c|c|c|c|}
\hline \multirow{2}{*}{ Shooting } & \multicolumn{2}{|c|}{$\stackrel{\text { Pre-TRUCE }}{\mathrm{SD}}$} & \multicolumn{2}{|c|}{$\stackrel{\text { Post-TRUCE }}{\mathrm{M}}$} & \multirow[t]{2}{*}{ Change } & \multirow[t]{2}{*}{ t-test sig } \\
\hline & & & & & & \\
\hline Target area & 4.00 & $(2.24)$ & 5.95 & $(4.22)$ & 1.95 & .084 \\
\hline Area A & 3.26 & $(2.75)$ & 4.00 & $(2.24)$ & .74 & .370 \\
\hline Area B & 4.68 & $(2.85)$ & 4.79 & (2.39) & .11 & .903 \\
\hline Area $\mathrm{C}$ & 2.32 & (1.97) & 2.63 & (1.54) & .31 & .585 \\
\hline Assauttstget area & 38.84 & $(8.03)$ & 36.11 & $(6.91)$ & -2.73 & .268 \\
\hline Area A & 59.47 & $(8.97)$ & 67.16 & (13.67) & 7.69 & .048 \\
\hline Area B & 57.79 & $(8.28)$ & 56.16 & $(10.27)$ & -1.63 & .593 \\
\hline Area $\mathrm{C}$ & 40.63 & $(5.03)$ & 42.47 & $(8.02)$ & 1.84 & .402 \\
\hline All vieleent ${ }_{t}$ area & 46.95 & $(9.27)$ & 45.68 & $(8.89)$ & -1.27 & .671 \\
\hline Area A & 70.79 & (10.32) & 77.84 & $(15.21)$ & 7.05 & .103 \\
\hline Area B & 70.11 & (11.93) & 66.16 & (11.83) & -3.95 & .313 \\
\hline Area $\mathrm{C}$ & 46.05 & $(5.94)$ & 47.63 & $(8.76)$ & 1.58 & .520 \\
\hline
\end{tabular}

Notes. Pre-TRUCE refers to the 19-month mean prior to implementation and the Post-TRUCE value is the mean of the 19 months after implementation. 
Table 5 displays the effects related to the dosage of TRUCE implementation by month. The first effect, Truce Implementation, is simply a dichotomous variable for the target area post-implementation. This tells us that the implementation of the TRUCE project was related to a significant increase in shootings, and a significant decrease in assaults. Specifically, the program's implementation corresponded to an increase of 3.2 shootings, a decrease of more than 16 assaults per month, and an overall decrease of more than 16 violent incidents per month. However, the reduction in our overall measure of violence was largely driven by the assault category. Further analysis of the data indicated that there were two months where the number of shootings (November and December 2010) were abnormally high; however, even after removing these two months from the analysis, the direction and the significance of the findings remained the same.

In terms of specific dosage levels, we found that the number of active clients per month and number of contacts with clients were significantly related to increases in shootings. One should note, however, that these increases were small, the largest being an increase of .07 shootings per month. Differently, for every conflict that was mediated by TRUCE staff, we found a decrease of almost two assaults (1.9) and a decrease of almost three violent crimes (2.7) overall. Additionally, each conflict mediation had a specific number of people involved, and the number of people involved in a mediation was related to our outcome measures. Specifically, for each additional person who was involved in a mediated conflict there was about a fifth of a call reduction in assault (.17) and a fifth of a call reduction for all violent (.20) incidents per month.

Table 6 shows the effects of client selection on the number of violent incidents. The analysis indicated that a number of the client characteristics were related to slight, but significant, increases in shootings. Specifically, whether they were female, increases in the number of core gang member clients, clients with a prior criminal history, and high-risk clients were all significantly related to an increase in the number of shootings in the target area. Differently, there were four client characteristics that were significantly related to reductions in assaults. An increase of one active gang member client reduced assaults by 3.3 per month. An increase in one client with recent violent victimization experience reduced assaults by one per month and having an additional client in the target age range corresponded to a reduction of more than 2.3 assaults per month. Finally, an increase of one client per month who had been recently released from prison was related to a reduction of 5.7 assaults per month.

Table 6 shows the effects of the variation in risk reduction activities implemented by TRUCE on the number of shootings, assaults, and overall violent incidents. Again, a number of activities were significantly related to increases in shootings. Two of the activities, unemployed clients (.38) and 
Table 5 Effect of program dosage on violence by incident type

\begin{tabular}{|c|c|c|c|c|c|c|c|c|c|}
\hline \multirow[b]{2}{*}{ Predictor } & \multicolumn{3}{|c|}{ Shooting } & \multicolumn{3}{|c|}{ Assault } & \multicolumn{3}{|c|}{ All violent } \\
\hline & Coef. & SE & Effect size & Coef. & SE & Effect size & Coef. & SE & Effect size \\
\hline TRUCE Implementation & $3.201^{*}$ & $(1.30)$ & 1.43 & $-16.436^{* *}$ & (5.13) & -2.05 & $-16.575^{* *}$ & $(6.36)$ & -1.79 \\
\hline Number of clients & $.074^{*}$ & $(.04)$ & .03 & -.275 & $(.16)$ & -.03 & -.205 & $(.18)$ & -.02 \\
\hline Number of contacts & $.007 *$ & $(.00)$ & .00 & -.023 & (.01) & .00 & .023 & $(.02)$ & .00 \\
\hline Number of home contacts & .023 & $(.01)$ & .01 & -.073 & $(.05)$ & -.01 & -.068 & $(.06)$ & -.01 \\
\hline Number of street contacts & .039 & $(.03)$ & .02 & -.159 & (.09) & -.02 & -.202 & $(.11)$ & -.02 \\
\hline Hours spent with clients & .001 & $(.00)$ & .00 & -.005 & $(.00)$ & .00 & -.005 & $(.00)$ & .00 \\
\hline Conflicts mediated & .275 & $(.27)$ & .12 & $-1.901^{* *}$ & $(.72)$ & -.24 & $-2.660^{* *}$ & $(.85)$ & -.29 \\
\hline Number of people in conflicts & .028 & $(.03)$ & .01 & $-.17 *$ & $(.07)$ & -.02 & $-.200^{*}$ & $(.09)$ & -.02 \\
\hline
\end{tabular}

${ }^{*} \mathrm{p}<.05$.

${ }^{* *} \mathrm{p}<.01$. 
Table 6 Effect of client selection and risk reduction on violence by incident type

\begin{tabular}{|c|c|c|c|c|c|c|}
\hline \multirow[b]{2}{*}{ Predictor } & \multicolumn{2}{|c|}{ Shooting } & \multicolumn{2}{|c|}{ Assault } & \multicolumn{2}{|c|}{ All Violent } \\
\hline & Coef. & SE & Coef. & SE & Coef. & SE \\
\hline \multicolumn{7}{|l|}{ Client selection } \\
\hline Male clients & .093 & $(.05)$ & -.336 & $(.21)$ & -.253 & $(.25)$ \\
\hline Female clients & $.290^{*}$ & $(.13)$ & -1.036 & $(.55)$ & -.777 & (.64) \\
\hline Gang involved clients & .588 & $(.36)$ & $-3.329^{* *}$ & $(.87)$ & $-3.795^{* *}$ & (1.04) \\
\hline Core gang member clients & $.130^{*}$ & $(.06)$ & -.388 & $(.27)$ & -.270 & $(.31)$ \\
\hline $\begin{array}{l}\text { Clients with prior criminal } \\
\text { history }\end{array}$ & $.090^{*}$ & $(.05)$ & -.351 & $(.19)$ & -.258 & $(.22)$ \\
\hline High-risk clients & $.089 *$ & $(.04)$ & -.323 & $(.19)$ & -.244 & $(.22)$ \\
\hline Recent victims of violence & .187 & $(.11)$ & $-.973^{*}$ & $(.47)$ & -.964 & $(.54)$ \\
\hline Clients aged $16-25$ & .291 & $(.30)$ & $-2.334^{* *}$ & $(.85)$ & $-3.396^{* *}$ & $(.99)$ \\
\hline $\begin{array}{l}\text { Clients with recently } \\
\text { incarcerated }\end{array}$ & .863 & $(.78)$ & $-5.654 * *$ & $(1.91)$ & $-5.999^{* *}$ & $(2.33)$ \\
\hline \multicolumn{7}{|l|}{ Risk reduction } \\
\hline Unemployed clients & $.382^{* *}$ & $(.15)$ & -.637 & (.63) & -.214 & $(.73)$ \\
\hline Discussed problem-solving & $.013^{*}$ & $(.01)$ & -.042 & $(.02)$ & -.044 & $(.03)$ \\
\hline Mediated client conflict & .004 & $(.18)$ & -.641 & $(.46)$ & -.714 & $(.55)$ \\
\hline $\begin{array}{l}\text { Referred clients to anger } \\
\text { management }\end{array}$ & -4.237 & $(3.04)$ & 2.503 & $(7.27)$ & -.118 & $(8.97)$ \\
\hline Discussed employment & $.047^{*}$ & $(.02)$ & -.086 & $(.06)$ & -.057 & $(.08)$ \\
\hline Assisted with job readiness & .341 & $(.22)$ & .011 & (.68) & .293 & $(.81)$ \\
\hline Assisted with job preparation & $.097 *$ & (.04) & -.205 & $(.13)$ & -.104 & $(.16)$ \\
\hline Discussed substance abuse & .046 & $(.02)$ & -.116 & $(.07)$ & -.124 & $(.09)$ \\
\hline $\begin{array}{l}\text { Referred to substance abuse } \\
\text { treatment }\end{array}$ & -.118 & (.90) & .052 & $(2.22)$ & -.874 & $(2.66)$ \\
\hline Discussed educational issues & $.036^{* *}$ & $(.01)^{* *}$ & & $(.05)$ & $-.0127^{*}$ & $(.06)$ \\
\hline Referred to education program & $.546^{* *}$ & $(.20)$ & -.376 & $(.54)$ & .175 & $(.65)$ \\
\hline
\end{tabular}

$* \mathrm{p}<.05$.

$* * \mathrm{p}<.01$.

referred to education program (.55), were significantly related to an increase of about one half of a shooting per month. Interestingly, for every additional client that was referred to anger management, there was a reduction of more than four shootings per month. This effect was not significant largely because there were so few referrals to anger management. Discussing problem solving with nonviolent means (.01), discussing employment needs (.05), discussing educational needs (.04), and assisting with job preparation (.10) were all significantly associated with increases in shooting incident reports, although none were substantively influential. The only risk reduction activity that significantly reduced the number of assaults was discussing educational issues with

clients. 


\section{FOX ET AL.}

\section{Discussion}

In the present study, we examined the implementation of the Phoenix TRUCE project and the impact the project had on neighborhood levels of violence. The Phoenix TRUCE Project was modeled after the Chicago CeaseFire program, which takes a public health approach in responding to violence in the community. We first examined the fidelity of program implementation. We next examined the impact of the project through a pre-test/post-test nonequivalent

10 control group design. Specifically, we examined data from the targeted neighborhood and three comparison neighborhoods before and after program implementation.

The implementation findings indicated that several of the programming components were implemented fully. For instance, all program participants $(100 \%)$ 15 in Phoenix met the qualifications for being at high risk for violence compared to $84 \%$ in Chicago. Likewise, the risk factors associated with individual's participating in programming was fairly similar across city's: about $89 \%$ of participants in Phoenix were gang involved compared to $92 \%$ in Chicago; $85 \%$ of participants in Phoenix had a prior history of offending compared to $91 \%$ in 20 Chicago, and $26 \%$ of participants in Phoenix reported being a recent victim of a shooting compared to $8 \%$ in Chicago (Skogan et al., 2009). Similar to Chicago and Baltimore, the majority of contacts made with participants in Phoenix were held in-person(e.g. home, street, and office) (Skogan et al., 2009; Webster, Whitehill, Vernick, \& Curriero, 2012). The Phoenix TRUCE project also held substantially more community events when compared to some other sites. Phoenix, for instance, held about 15-17 community events per month com- pared to about 1-2 a month in Baltimore (Webster, Whitehill, Vernick, \& Par- ker, 2012). Additionally, the local police department regularly intelligence about violence to outreach and crisis intervention workers.

30 Our analysis, however, also found that the TRUCE program might have not been as robust in other areas of implementation. For example, Chicago conducted about 6.6 mediations a month and these mediations primarily focused on retaliations, gang rivalries, and property conflicts (Skogan et al., 2008). Phoenix's mediation activity looked a lot more similar to that of Pittsburgh and 35 Baltimore where about two to three mediations were conducted each month and these mediations were often focused on gang conflict, personal disputes, domestic violence, and drugs (Whitehill et al., 2012; Wilson et al., 2010). Likewise, while Phoenix demonstrated a strong commitment to the public education component of the program, the program might not have been as well known as

40 they were in other communities. In Baltimore, for example, almost $70 \%$ of residents had observed CeaseFire materials (Webster, Whitehill, Vernick, \& Parker, 2012) compared to $30 \%$ in Phoenix (citation removed for review purposes).

Our analysis also indicated that comprehensive community embeddedness was never formally implemented (e.g. no community advisory board, no 45 involvement with the faith-based community). This potentially resulted in lack 
of strategic direction for the program and reduced the program's capacity to mobilize larger institutions to change the culture of violence within the community. This also might have necessarily resulted in fewer opportunities for clients to access jobs and services. While these aspects of the program deviated from protocol, clients in Phoenix were contacted frequently and appear to have been referred to the same types of services as those in other sites, albeit client contacts were on average shorter in duration in Phoenix (Webster, Whitehill, Vernick, \& Parker, 2012). Furthermore, CPLC, the program implementer, is one of the state's premier NGOs. It is responsible for providing resources related to housing, education, employment, employment training, behavior health, and a variety of other social services. It is well entrenched in the community and has the capacity to provide most of the services required of CeaseFire. As a result, while the implementing organization did not reach out to the community for this particular initiative, it had the capacity to provide substantial services to clients.

Our findings also suggested that the Chicago CeaseFire model as it pertains to targeting a densely populated neighborhood with high levels of violence may not translate well to more suburban communities, such as those located in the Southwest. For example, Chicago has about 4.25 times the number of residents per square mile than Phoenix (11,841.8 vs. 2,797.7). Chicago is also characterized by large tenant high rises, substantial pedestrian traffic, and reliance on public transportation (e.g. train, cabs), which results in violence being highly concentrated in fairly small geographic areas (Morenoff \& Sampson, 1997). Phoenix neighborhoods, on the other hand, are characterized by scattered development, single-family homes, high use of private automobile transportation, and little pedestrian traffic. Because of population decentralization, violence is relatively dispersed (Robinson et al., 2009). For example, the Hermoso Park neighborhood (a 1 mile by 1.5 mile area) was found to be one of the most violent in the state, but yet only experienced four homicides in the 12-months prior to the intervention. Regardless of these spatial attributes, Chicago advisors strongly believed that replication of the program required it to be implemented in a small geographic area. It is unclear what impact these geo-spatial characteristics have on program implementation, and is an important issue for policy-makers and researchers to consider in the future. It could be that communities such as Phoenix might be better served by hospital-based violence intervention programs that prescribe similar methods of intervention but participants are recruited through hospital admissions rather than neighborhood activity (see e.g. Cooper, Eslinger, \& Stolley, 2006). Future researchers should examine the costs and benefits between faithful replication and appropriate adaptability to local context given the vast differences is sites that are implementing CeaseFire (Columbus, Ohio, Port of Spain, Trinidad, Iraq, New York City, etc.).

Our findings related to the impact of the TRUCE project were just as mixed. The primary goal of the intervention was to reduce shootings. Our analysis, however, showed that program implementation was associated with an 45 
increase in shootings. As seen in Table 5, Cohen's effect size value $(d=1.43)$ suggested that this change was large, substantively speaking. Specifically, we found that the implementation of TRUCE corresponded to an increase of 3.2 shootings, on average, per month, controlling for the comparison areas and the trends in the data. Furthermore, our analysis showed that as the number of clients and contacts by outreach workers increased, so did shootings; although these effects were very small. These findings are consistent with those found by Wilson and Chermak (2011) in their study of a CeaseFire program in Pittsburgh. It is possible that the TRUCE program's deviation from implementation protocol resulted in the boomerang effect. Or it could be that the programming itself was tied to an increase in shootings.

One possibility is that the shootings in Phoenix, which are often tied to gang rivalries, are largely a reflection of community norms that are supportive of retaliatory violence. A core component of the CeaseFire model involves faith-

15 based leaders and community coalitions against violence. As noted above, this component was largely absent in the implementation of the Phoenix TRUCE project. While CPLC's organizational capacity allowed them to sufficiently provide client services, which in other sites are typically provided through a number of local service providers vis-a-vis a community coalition, the lack of 20 community embeddedness, lack of involvement by the faith-based community, and the lack of public knowledge about the project might have prohibited the program from altering the norms and values of the community away from shootings and toward the peaceful resolution of conflict.

Another explanation for the increase in shootings is also plausible. Prior research dating back to the 1960s has suggested that street outreach can result in the unintended consequence of increasing neighborhood levels of gang membership and delinquency. For example, Klein (1971) reported that the assignment of caseworkers increased the local reputation of particular gangs, which helped to attract new members, and led to an increased gang problem in the areas employing detached workers. Spergel (1995) reported similar findings in his examination of a program that was designed to provide job training and job opportunities for gang members in Chicago. Project staff were primarily comprised of gang leaders from two of the largest gangs in Chicago. The analyses indicated that the project was a failure by almost all accounts. Job

35 training and placement efforts were unsuccessful as gang structures became more sophisticated, and gang-motivated homicides increased.

Much more research is needed to determine the causal mechanisms that result in such a boomerang effect. If implementation failures are responsible, causal components should be identified and policy-makers and practitioners

40 should be warned about potential adverse effects if programming deviates from that which is prescribed. If particular components (e.g. street outreach work) actually cause some forms of violence to increase, their use should be moderated to only those situations that necessitate their implementation.

With the above said, a secondary concern of the present study was to examine the impact of the program on other forms of violence. We found that the 
TRUCE project had a large and significant impact on assaults and other violent crime. As seen in Table 5, Cohen's effect size (d) values were -2.05 for assault and -1.79 for all violent crime. Time-series analysis indicated that program implementation corresponded to a decrease of more than 16.6 total violent incidents and 16.4 assaults on average per month, when controlling for the comparison areas and the trends in the data. Coupled with our implementation data these findings suggest that the more conflicts that were mediated (d $=-.24)$ and the more people involved in mediated conflicts $(\mathrm{d}=-.29)$, caused a greater decrease in assaults. Likewise, our analyses revealed that assaults sub- stantially decreased as the program increased in the number of clients who 10 were gang-involved $(\mathrm{d}=-1.35)$, aged $16-25(\mathrm{~d}=-.95)$, recent victims of violence $(\mathrm{d}=-.39)$, and recently released from prison increased $(\mathrm{d}=-2.3){ }^{15}$

While we can only speculate as to the reason for the decline in assaults and other forms of violence, it might be that the Phoenix TRUCE program's emphasis on mediations involving personal altercations and domestic violence, which represented $50 \%$ of mediations in Phoenix, might have directly impacted the crimes associated with our measures of assault. In other words, the benefits of the project might have been restricted to those problems that the project disproportionately focused on-personal altercations. It might be that gang violence, which is often expressed through shootings; and assaults, which are often a result of personal altercations, are differentially impacted by mediation and community mobilization. Mediations might be an effective strategy for responding to assaults because their origins are more likely based on personal, and not group level, conflict. Conversely, in the absence of community mobilization tactics that changes neighborhood cultural norms about violence, mediation, and street outreach left on their own might amplify gang-related violence as discussed above.

Taken together, these findings suggest that while some components of the CeaseFire strategy (and specific types of clients) are associated with positive outcomes for some forms of violence (i.e. assaults); other components might have led to a boomerang effect for other forms of violence (i.e. shootings). By lumping all of these components and their activities together under a broad measure of "intervention," might have masked those particular components of the program that were driving positive (and negative) outcomes. Identifying those components that have the greatest effect on violence reduction can help policy-makers design more effective and efficient programs in the future. Strategies such as Chicago CeaseFire often become a cocktail of interventions focused on a specific area and type of people. Researchers may know that each of the components of the intervention works independently, but we rarely know how well they work when administered simultaneously. Just as the interaction between some medications can result in an adverse reaction for a

15. We do not add the effect sizes for of client selection on violence by incident type due to space limitations. For this information contact the authors. 
patient; policy-makers and researchers should also be attuned to the fact that multiple treatments in a community can backfire; even if those treatments come from the same program.

Prior to the interpretation of the findings being complete we note three limitations to the present study. First, the Phoenix TRUCE project might not serve as an ideal replication of the Chicago CeaseFire given the geo-spatial differences between Chicago and Phoenix as noted above. Second, the main goal of Chicago CeaseFire model is to reduce homicides, however, given the low number of homicides in the TRUCE target area the project could not be evaluated based on this criterion. Third, given our use of a nonequivalent control group design our findings might have been subject to sampling bias because our comparison areas were not perfectly matched. For example, the targeted neighborhood was comprised of a substantial number of African-American residents (40\%) when compared to the three comparison areas (4-10\%). This issue is of particular importance given the potential of differences between African-American and Hispanic gangs in Phoenix. Prior research suggests that almost $80 \%$ of gang members in Phoenix are Hispanic and about $15 \%$ are African-American. Related, anecdotal evidence suggests that African-American gangs in Phoenix 20 are more violent and more eavily involved in street-level drug trafficking than Hispanic gangs and that s, sang violence in Phoenix is largely intra-racial, in part because of segregat . $\gamma$ adjacent turf boundaries. (Katz \& Webb, 2006). Therefore, it is possible tha. selection of the target area, and the subsequent inclusion of a sn $r$ - ortion of African-American clients in the target area might have inc ased the probability of clients being involved in violence when compared to 'ose $\mathrm{li} \cdot \mathrm{g}$ in the comparison areas. With the above said communities in tho I In $\mathrm{n}_{\mathrm{w}}$, tates and elsewhere have been eagerly looking for a silver bullet reau violence. The result has been a rush to adopt the Chicago CeaseFir nodel, $b$ ieving that it is an effective model that has the 30 potential to $\mathrm{dr}^{\wedge} \mathrm{m}_{\mathrm{i}}$ ally $r$ uce violence. Combined, evaluations of the Chicago CeaseFire nodel nave demonstrated that such a complex strategy can be implemented. fairly short period of time. Especially when compared to other shensı trategies to respond to gangs (e.g. the Spergel Model). How rer, or findings, coupled with others suggest that thorough evaluations of 35 the chicagr Leasefire model continue to be needed in a variety of contexts and envı. $n$ its. It is still unclear whether the model results in decreased violence, ha. impact on violence, or it increases violence.

It might be . lat the varying results between sites are the consequence of an interaction between site selection and the proscribed treatment. Chicago and Baltimore are both chronic gang cities that have had long-standing gang problems (Spergel \& Chak, 1990). Their gangs have traditionally been more organized and cohesive (Burns, 2003; Decker, Bynum, \& Weisel, 1998). Conversely, Phoenix and Pittsburgh have been characterized as emerging gang cities (Spergel \& Chak, 1990). Gang problems in these two communities have not been as 45 organized or as cohesive (Decker, Katz, \& Webb, 2008; Wilson \& Chermak, 2011). As alluded to by Wilson and Chermak (2011), the interaction between 
the treatment and the nature of the community's gang problem might have resulted in divergent results between replication sites. In Phoenix where gangs are loosely organized and lack substantial cohesion, it is possible that outreach workers might have increased participation in gangs, increased gang cohesion, and increased gun-related violence. However, we lack the data to examine this possibility. In the future, replications of Chicago Ceasefire might consider adding a research component that examines changes in the gangs and gang cohesion prior to and during program implementation.

Regardless, those who are implementing (or who are planning to implement) the program should be alerted to the potential for adverse effects, and monitoring and evaluation of the program should be given high priority so that any unintended consequences can be addressed sooner rather than later if required.

\section{Acknowledgements}

This research was funded by Chicanos Por La Causa, Inc., through a grant from the Bureau of Justice Assistance (2009-SC-B9-0051). Opinions contained herein are those of the authors and do not represent the position of Chicanos Por La Causa, Inc., the Bureau of Justice Assistance, Office of Justice Programs, U.S. Department of Justice, or any of the partner agencies of the Phoenix TRUCE Project. This project was approved by the Institutional Review Board at Arizona State University (No. 100500).

\section{References}

Arizona Criminal Justice Commission. (2004). Violence impact project: A multi-governmental strategy against violence. Arizona Criminal Justice Commission: Phoenix, AZ.

Block, C., \& Block, R. (1993). Street gang crime in Chicago. Washington, DC: National Institute of Justice, Office of Justice Programs, U.S. Department of Justice.

Boyle, D. J., Lanterman, J. L., Pascarella, J. E., \& Cheng, C.-C. (2010). The impact of Newark's operation ceasefire on trauma center gunshot wound admissions. Justice Research and Policy, 12, 105-123.

Burns, E. (2003). Gang and drug-related homicide: Baltimore's successful enforcement strategy. Bureau of Justice Assistance Bulletin, July. Washington DC: Bureau of Justice Assistance.

Bursik, R. J., Harold, G., \& Grasmick, H. G. (1993). The use of multiple indicators to estimate crime trends in American cities. Journal of Criminal Justice, 21, 509-516.

Chaskin, R. (2010). Youth gangs and community intervention. New York, NY: Columbia University Press.

Ceasefirechicago.org (2012). Found at Casefirechicago.org in October 2012.

Cooper, C., Eslinger, D. M., \& Stolley, P. D. (2006). Hospital-based violence intervention programs work. The Journal of Trauma: Injury, Infection, and Critical Care, 61, 534540.

Decker, S. H., Bynum, T., \& Weisel, D. (1998). A tale of two cities: Gangs as organized crime

15 , 395-425. 
Decker, B., Featherstone, J., Cantillon, D., \& Slutkin, G. (2013). Implementation of cure violence in international and institutional settings: The experience of England. Presented at the Annual meeting of the American Public Health Association. Boston, MA.

Decker, S. H., Katz, C. M., \& Webb, V. J. (2008). Understanding the black box of gang organization implications for involvement in violent crime, drug sales, and violent victimization. Crime \& Delinquency, 54, 153-172.

Felson, R., \& Steadman, H. (1983). Situational factors in disputes leading to criminal violence. Criminology, 21, 59-74.

Fenton, J. (2012). Safe streets violence mediation program coming to West Baltimore. The Baltimore Sun. Retrieved October 4, from http://www.baltimoresun.com/news/ breaking/bs-md-ci-mondawn

Green-Mazerolle, L. J., Ready, J., Terrill, W., \& Waring, E. (2000). Problem-oriented policing in public housing: The Jersey City evaluation. Justice Quarterly, 17, 129158.

Katz, C. M., \& Choate, D. (2006). Diagnosing Trinidad \& Tobago's GANG Problem. Presented at the Annual Meeting of the American Society of Criminology, Los Angeles, California.

Katz, C. M., \& Webb, V. J. (2006). Policing gangs in America. New York, NY: Cambridge University Press.

Katz, C. M., Wallace, D., \& Hedberg, E. C. (2011). A longitudinal assessment of the impact of foreclosure on neighborhood crime. Journal of Research in Crime and Delinquency. Online December 26.

Katz, C. M., Webb, V. J., \& Schaefer, D. R. (2001). An assessment of the impact of quality-of-life policing on crime and disorder. Justice Quarterly, 18, 825-876.

Kelly, J. (2010). Did ex-cons run a gang from their youth program? Youth Today. Retrieved October 4, 2012, from http://www.youthtoday.org/view_article.cfm? article_id=3959

Klein, M. W. (1971). Street gangs and street workers. Englewood Cliffs, NJ: PrenticeHall.

Klofas, J. M., Hipple, N. K., \& McGarrell, E. F. (2010). The new criminal justice: American communities and the changing world of crime control. New York, NY: Routledge.

Krug, E., Mercy, J. A., Dahlberg, L. L., Zwi, A. B., \& Lozano, R. (2002). The world report on violence and health. The Lancet, 360, 1083-1088.

Maguire, E. (2012). Chicago's Ceasefire and the community based violence interruption movement. Unpublished manuscript. Washington DC: American University (Chapter 40 8).

Morenoff, J. D., \& Sampson, R. J. (1997). Violent crime and the spatial dynamics of neighborhood transition; Chicago, 1970-1990. Social Forces, 76, 31-64.

Papachristos, A. V., Braga, A. A., \& Hureau, D. M. (In press). Six-degrees of violent victimization: Social networks and the risk of gunshot injury.

Papachristos, A. V., Meares, T., \& Fagan, J. (2007). Attention felons: Evaluating project safe neighborhoods in Chicago. Journal of Empirical Legal Studies, 4, 223-272.

Perkins, C. (2003). National crime victimization survey, 1993-2001: Special Report. Washington, DC: US Department of Justice, Office of Justice Programs, National Institute of Justice.

Podesta (2000). Retrieved December 14, 2011, from http://duke.edu/ kkk4/Fall_07/ Paper/Podesta_Pooled_Time_Series_Cross_Section.pdf

Pokorny, A. (1965). Human violence: A comparison of homicide, aggravated assault, suicide, and attempted suicide. The Journal of Criminal Law, Criminology, and Police Science, 56, 488-497.

Portillos, E. L., Jurik, N. C., \& Zatz, M. S. (1996). Machismo and Chicano/a Gangs: Symbolic resistance or oppression? Free Inquiry in Creative Sociology, 24, 175-183. 
Ritter, N. (2009). CeaseFire: A public health approach to reducing shootings and killings. NIJ Journal, 264, NCJ 228386.

Robinson, P. L., Boscardin, W., George, S. M., Teklehaimanot, S., Heslin, K. C., \& Bluthenthal, R. N. (2009). The effect of urban street gang densities on small area homicide incidence in a large metropolitan county, 1994-2002. Journal of Urban Health, 86, 511-523.

Shacter, A. (2009). Firearm-related injuries among residents of the Phoenix Police Department South Mountain Precinct, Arizona 2008. Phoenix, AZ: Arizona Department of Public Health.

Sherman, L., Gartin, P., \& Buerger, M. (1989). Hot spots of predatory crime: Routine activities and the criminology of place. Criminology, 27, 27-56.

Sherman, L., \& Rogan, D. (1995). Deterrent effects of police raids on crack houses: A randomized, controlled experiment. Justice Quarterly, 12, 4.

Skogan, W. G., Hartnett, S. M., Bump, N., \& Dubois, J. (2008). Evaluation of CeasefireChicago. Washington, DC: US Department of Justice, Office of Justice Programs, National Institute of Justice.

Spergel, I. (1995). The youth gang problem. New York, NY: Oxford University Press.

Spergel, I. A., \& Chak, A. (1990). Survey of youth gang problems and programs in 45 cities and 6 sites. Chicago, IL: University of Chicago, School of Social Service Administration.

Webster, D., Vernick, J. S., \& Mendel, J. (2009). Interim evaluation of Baltimore's safe streets program. Baltimore, MD: Center for the Prevention of Youth Violence, the Johns Hopkins Bloomberg School of Public Health.

Webster, D., Whitehill, J., Vernick, J., \& Curriero, F. (2012). Effects of Baltimore's safe streets program on gun violence: A replication of Chicago CeaseFire Program. Journal of Urban Health. doi:10.1007/s11524-012-9731-5 (Online First).

Webster, D., Whitehill, J., Vernick, J., \& Parker, E. (2012). Evaluation of the safe streets program. Baltimore, MD: The Johns Hopkins School of Public Health.

Wilson, J. M., \& Chermak, S. (2011). Community driven violence reduction programs. Criminology \& Public Policy, 10, 993-1027.

Wilson, J. M., Chermak, S., \& McGarrell, E. F. (2011). Community-based violence prevention: An assessment of Pittsburgh's One Vision One Life program. Santa Monica, CA: RAND Corporation.

Zatz, M. S., \& Portillos, E. L. (2000). Voices from the barrio: Chicano/a gangs, families, and communities. Criminology, 38, 369-402.

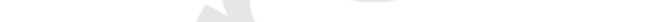

